\title{
Coherent Synoptic Disturbances in the Australian Monsoon
}

\author{
GARETH J. BERRY AND Michael J. REEDER \\ Monash Weather and Climate, School of Mathematical Sciences, Monash University, Clayton, Victoria, Australia \\ CHRISTIAN JAKOB \\ ARC Centre of Excellence for Climate System Science, School of Mathematical Sciences, \\ Monash University, Clayton, Victoria, Australia
}

(Manuscript received 13 March 2012, in final form 3 June 2012)

\begin{abstract}
Coherent synoptic-scale weather systems within the Australian monsoon are identified and tracked in the isentropic potential vorticity (PV) field from the ECMWF Interim Reanalysis (ERA-Interim) dataset during the Southern Hemisphere summer. The resulting dataset is then used to compile statistics and synoptic composites of Australian monsoon disturbances. On average, a synoptic system is found in the region every 2.5 days. However, the time interval between consecutive events is highly variable, meaning that the synoptic activity in the Australian monsoon is not well represented by commonly employed spectral techniques. The analysis reveals that most synoptic systems originate within the Australian monsoon, but at the $315-\mathrm{K}$ level (approximately $700 \mathrm{hPa}$ ) a significant proportion of systems are first detected near the east coast of the continent where extratropical Rossby waves are observed to frequently break.

The average Australian monsoon weather system propagates from east to west at approximately $6 \mathrm{~m} \mathrm{~s}^{-1}$ and has a characteristic length scale of $2000 \mathrm{~km}$. Synoptic composite structures show some resemblance to African easterly waves; they move along a midtropospheric (approximately $700 \mathrm{hPa}$ ) easterly wind maximum and have peak meridional winds at this level. Composite rainfall shows that rainfall is significantly enhanced ahead (west) of the synoptic PV maximum and suppressed behind. It is estimated that in some parts of northwestern Australia $40 \%-50 \%$ of the summertime rainfall occurs with a tracked monsoon disturbance in the vicinity.
\end{abstract}

\section{Introduction}

Synoptic-scale weather systems are frequently observed in the tropics and are intimately linked to disturbed local weather conditions. Perhaps the best documented synoptic systems are African easterly waves (AEWs) (e.g., Reed et al. 1977) and monsoon lows over the Indian subcontinent (e.g., Godbole 1977), both of which are important organizers of rainfall in their respective regions. These disturbances are readily identified by cyclonic vorticity with maxima in the middle or lower troposphere. Both AEWs and Indian monsoon lows are most frequently observed during summer and are generated within a monsoon environment. The aim

Corresponding author address: Gareth J. Berry, School of Mathematical Sciences, Monash University, Wellington Road, Clayton VIC 3800, Australia.

E-mail: gareth.berry@monash.edu of the research presented here is to explore synoptic analogs in the Australian monsoon in order to generate a climatology and to estimate their effect on regional rainfall.

Over tropical North Africa, AEWs are generated over the central and eastern parts of the continent and propagate westward through the West African monsoon, intensifying as they move toward the Atlantic Ocean (e.g., Carlson 1969). As these disturbances continue to move westward over the ocean, they may act as precursors for tropical cyclones in the tropical Atlantic or eastern Pacific. It has been shown that AEWs are fuelled by baroclinic and barotropic energy conversions from the monsoon-scale environment (particularly the midtropospheric African easterly jet (see, e.g., Norquist et al. 1977) as well as from deep moist convection embedded within the disturbance (see, e.g., Berry and Thorncroft 2012). AEWs have a length scale on the order of $3000 \mathrm{~km}$ and can persist for a week or more as they 

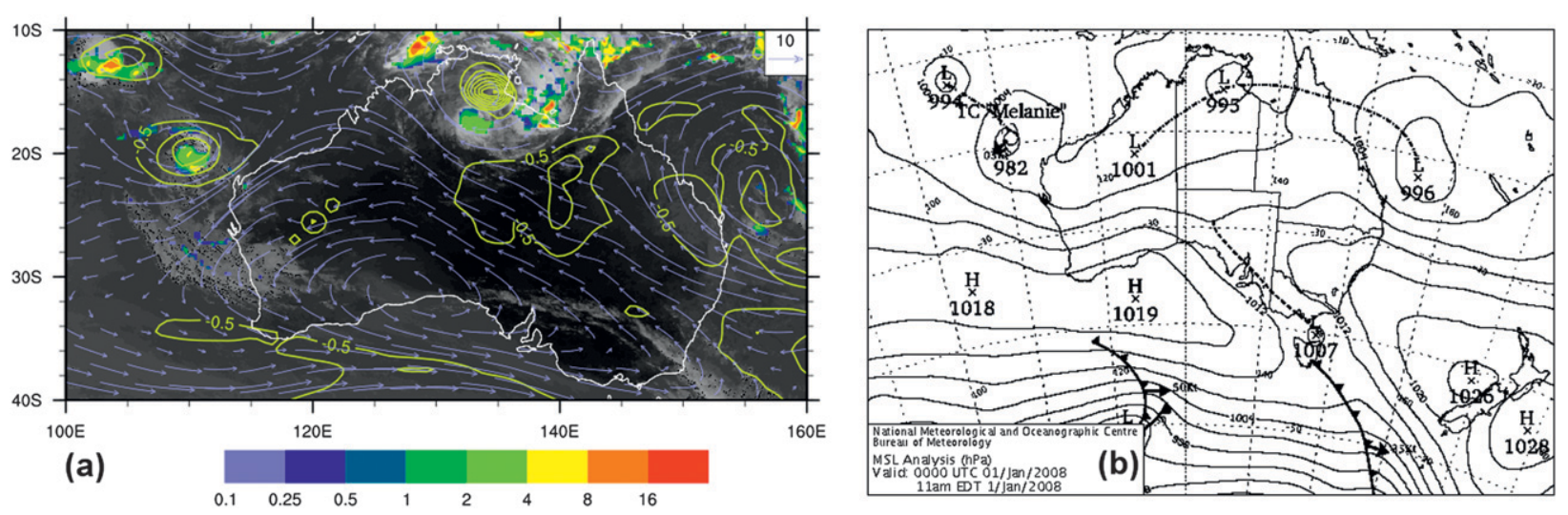

FIG. 1. (a) Example map for 0000 UTC 1 Jan 2008. Yellow lines show 315-K potential vorticity (multiplied by -1; drawn every 0.1 PVU) and wind vectors (blue) from the ERA-Interim reanalysis overlaid on TRMM 3B42 rainfall estimate (colored according to legend below panel) and Multifunctional Transport Satellite (MTSAT) infrared imagery (grayscale). (b) BOM surface analysis valid at 0000 UTC 1 Jan.

traverse the African continent and the Atlantic Ocean. They possess a relatively complex synoptic structure (including multiple vorticity centers and variable vertical tilts), due to their interaction with the large-scale environment and organized deep convection, which in many respects is analogous to midlatitude cyclones (see Berry and Thorncroft 2005).

By comparison, Indian monsoon lows are generated near the coast of India (around the Bay of Bengal) and propagate inland toward the continental heat low. These systems tend to be shorter lived than AEWs (2-5 days) and have smaller horizontal scales (approximately $1500 \mathrm{~km}$ ), which may reflect differences in the environment (see Krishnamurti et al. 1975). Composite studies of Indian monsoon lows (e.g., Godbole 1977) show that these disturbances are characterized by strong cyclonic vorticity from the surface to the upper troposphere, with relatively little vertical tilt. At the surface, these disturbances have been associated with wind gusts exceeding $40 \mathrm{kt}$ and heavy rainfall of $120 \mathrm{~mm} \mathrm{day}^{-1}$ or more on their western (leading) edge.

Monsoon depressions are also found within the Australian monsoon system during austral summer, although they have received considerably less attention than AEWs or Indian monsoon lows in the literature. The majority of studies concerned with Australian disturbances are focused on particular high impact cases (e.g., Davidson and Holland 1987; Hell and Smith 1998; Kong and Zhao 2010; Zhao and Mills 1991). The broad consensus from these studies is that Australian monsoon disturbances are similar to Indian monsoon depressions, although little is known about their life cycle or if the few events examined are representative. At present, there is no climatology of Australian monsoon depressions. The similar geography of Australia and North Africa was noted by Dickinson and Molinari
(2000), who compared the large-scale summertime basic state from an isentropic potential vorticity (PV) perspective and used bandpass-filtered (2-10 days) winds as a metric of synoptic activity. These authors determined that the background mean gradients of PV necessary to support small amplitude, growing, disturbances in the absence of convection were similar over both Australia and Africa but found that the synoptic activity over Australia was very weak, and no evidence of growing synoptic-scale disturbances was found. These authors suggested that this lack of synoptic activity could be linked to the smaller horizontal extent of the Australian monsoon or the lack of high terrain compared to the African region.

Although there is a paucity of scientific literature describing Australian monsoon lows, they are routinely monitored and frequently seen in operational products from the Australian Bureau of Meteorology (BOM), including the regular surface analysis, and are discussed as precursor disturbances in tropical cyclone (TC) reports [e.g., TC Erica (2003), TC Les (1998)]. An example of several simultaneous monsoon lows in the Australian region is shown in Fig. 1. A snapshot of the 315-K (approximately $700 \mathrm{hPa}$ in this region) isentropic $\mathrm{PV}$ and wind vectors with infrared satellite imagery and the Tropical Rainfall Measuring Mission (TRMM) 3B42 rainfall estimate (Huffman et al. 2007) is shown in Fig. 1a, and the subjective surface analysis from BOM is shown in Fig. 1b. This figure shows an intense monsoon low over the Top End of the Northern Territory (near $15^{\circ} \mathrm{S}$, $135^{\circ} \mathrm{E}$ ) signified by a subsynoptic-scale PV maximum. Cyclonic PV is negative in the Southern Hemisphere by convention but has been multiplied by -1 here in order to allow direct comparison with previous research pertaining to AEWs and Indian monsoon lows. This feature is associated with rainfall and cold cloud tops 
and a surface pressure minimum superimposed on the broad monsoon trough. Other tropical disturbances can be noted over the oceans; upstream there is a less convectively active cyclonic disturbance over the Coral Sea $\left(22^{\circ} \mathrm{S}, 157^{\circ} \mathrm{E}\right)$, which also lies on the monsoon trough, and downstream over the Indian Ocean there are two convectively active PV minima, one of which is a tropical cyclone (TC Melanie: $20^{\circ} \mathrm{S}, 110^{\circ} \mathrm{E}$ ). Consistent with the findings of the case study by Hell and Smith (1998), the monsoon lows in this region are well defined in the isentropic PV field, and this provides the primary identification diagnostic in the research presented here.

The aim of the work presented here is to provide an overview of the activity of coherent synoptic scale disturbances in the Australian region. This is motivated in part by the lack of literature as discussed above and by recent work by Berry et al. (2011b), who suggest that an increase in northwest Australian rainfall may be linked with changes in synoptic systems; here we will provide a quantitative estimate of how much rainfall can be attributed to monsoon lows. The methods for this research are described in section 2 , and a statistical overview is presented in section 3. Composite disturbance structure is presented in section 4 , and the results are discussed with main conclusions in section 5 .

\section{Methodology}

As shown by previous work (e.g., Hell and Smith 1998), Australian monsoon lows can be characterized by regions of intense cyclonic relative vorticity, which is mirrored by the isentropic PV as demonstrated in Fig. 1a In this study, long-lived cyclonic disturbances are identified in the isentropic PV field from the European Centre for Medium-Range Weather Forecasts Interim Reanalysis (ERA-Interim) dataset and tracked using a simple automated technique. Isentropic PV has been selected as the basis of this analysis as it retains the features of the relative vorticity field, and the conservation properties of PV (conserved by frictionless adiabatic processes and redistributed by internal diabatic heating) allow physical mechanisms to be identified. Using isentropic PV and its rate of change gives an opportunity to determine whether latent heating plays a significant role in the origin or evolution of particular disturbances. Those evolving through dry dynamics will likely have a continuous history and PV that only changes by advection on the isentropic surface, whereas disturbances in which latent heating has a large influence would be characterized by rapid nonadvective changes in their PV (see, e.g., Berry and Thorncroft 2005). The ERAInterim reanalysis data used here are provided on a $1.5^{\circ} \times$ $1.5^{\circ}$ horizontal grid every six hours for the period
1989-2009. The analysis is confined to the three isentropic surfaces, $315 \mathrm{~K}, 330 \mathrm{~K}$, and $350 \mathrm{~K}$, during the Southern Hemisphere warm season (November-March). The PV field is multiplied by negative one so that a PV maximum refers to a cyclonic feature throughout this study.

The algorithm used to identify and track coherent PV features on isentropic levels comprises four steps with necessary threshold values determined through direct experimentation and comparison with daily maps. First, the PV field is smoothed with two passes of a five-point averaging operator to reduce the impact of isolated convective systems and to make the tracks more continuous. Second, the data at each time step are scanned for all local PV maxima exceeding 0.01 PV unit (PVU $\equiv$ $10^{-6} \mathrm{~K} \mathrm{~m}^{2} \mathrm{~kg} \mathrm{~s}^{-1}$ ) that are separated by at least $3^{\circ}$ from adjacent maxima. This radius threshold with the smoothing effectively means that only PV maxima of $\sim 500 \mathrm{~km}$ and larger (i.e., mesoscale and synoptic scale) are tracked. Third, the horizontal wind components on each surface are interpolated to the location of each local maximum and, assuming the PV field evolves only through advection, used to forecast the position of each maximum at the next time step.

Finally, the positions of PV maxima at the subsequent time step are detected and their locations compared to the forecast positions of PV maxima detected at the initial time. Those within a radius of $5^{\circ}$ are associated with one another and joined to form a track. This value allows for some distortion of the PV maxima (and consequential jumps in the geometric center) but minimizes unphysical shifts in position. Only complete tracks lasting more than $24 \mathrm{~h}$ (four analysis times) are retained to ensure that the PV maxima detected are coherent weather systems and are used to form the basis of statistics and composites.

An example demonstrating the identification and tracking technique on the $315-\mathrm{K}$ isentropic surface in the ERA-Interim reanalysis is shown in Fig. 2. There are several PV maxima over northern Australia similar to those in Fig. 1. These maxima are all subsynoptic scale and conform to our conceptual expectations based on previous literature. The tracks overlaid show that each PV maximum in the tropics has propagated more than $1000 \mathrm{~km}$ from the east. Long-lived isolated PV maxima are also detected at higher latitudes (e.g., near $36^{\circ} \mathrm{S}$, $\left.167^{\circ} \mathrm{E}\right)$, although it should be recognized that tracking only commences once the feature becomes an isolated maximum, meaning that elongated maxima such as PV troughs or streamers are not detected or analyzed.

Composites of synoptic structures are formed from the ERA-Interim datasets by determining the dates on which PV maxima pass through a specific region. Data 


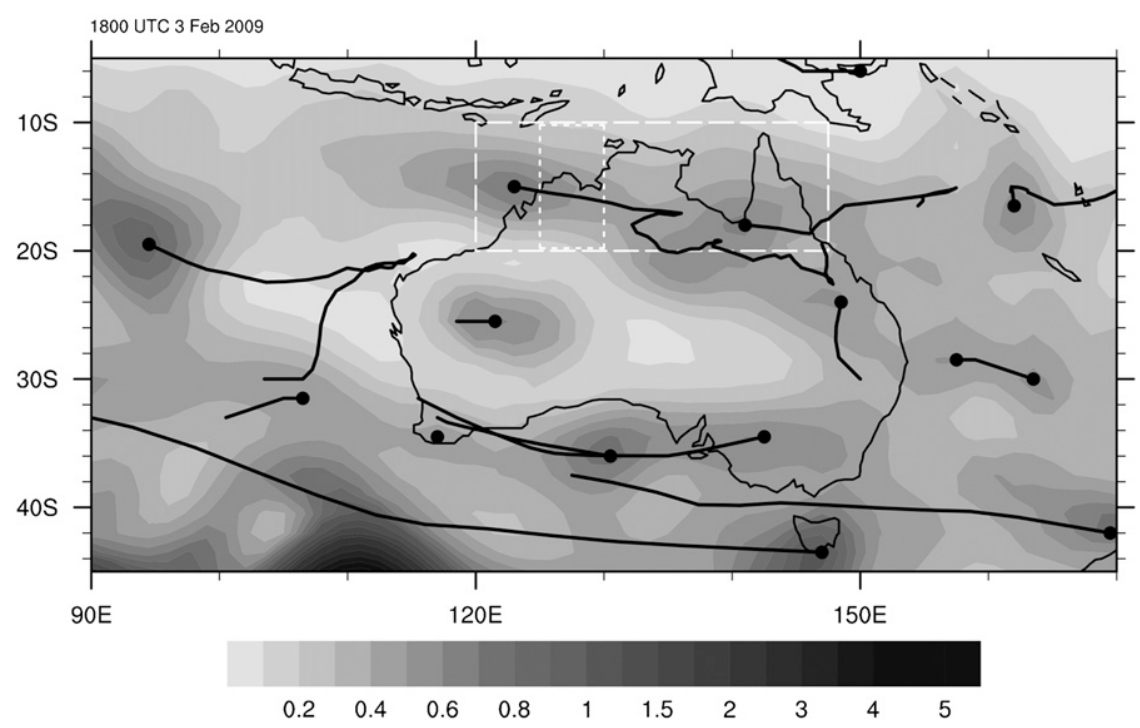

FIG. 2. Example of the PV maxima tracking algorithm. Shading shows the 315-K PV field (legend below panel) and the black dots denote the location of PV maxima identified by the tracking algorithm at the example time. Black lines show the tracks of the detected PV maxima from previous time periods. The boxes overlaid show the area used to define an Australian monsoon region (long white dashes) and the region used to construct the synoptic composite (short white dashes).

from these dates are extracted and the composite formed based on their arithmetic mean. Lag composites are generated by a simple averaging of instantaneous fields a prescribed number of days before or after the PV maxima pass the specified location. The Global Precipitation Climatology Project (GPCP) (Huffman et al.1997) daily dataset is used for the analysis of rainfall associated with the PV maxima. These data consist of daily totals for the period October 1996 to present, meaning that the composite rainfall fields are calculated using a subset of the dates from the tracking datasets. The closest time to that found by the tracking in the ERA-Interim is used to generate the GPCP composites. Because rainfall in the Australian monsoon has a clear seasonal progression (see, e.g., Suppiah 1992), GPCP anomalies are computed as a deviation from a time-varying mean. This time-varying mean is constructed by a low-pass filter of the daily means that retains only the first four harmonics of the seasonal cycle.

\section{Overall PV center behavior}

\section{a. Geographical distribution of $P V$ centers}

The total track density of coherent PV maxima on each of the isentropic levels is shown in Fig. 3. There is a track density maximum over northern Australia on all three levels, extending from the Gulf of Carpentaria into the eastern Indian Ocean, suggestive of a tropical "storm track." Poleward of $40^{\circ} \mathrm{S}$ at all three levels the track density is relatively low, presumably as a consequence of the PV maxima being defined by closed contours of PV; at these latitudes the PV maxima are likely to be associated with extended troughs.

At the lowest level (315 K, Fig. 3a), the track density is high over north-central Queensland (near 20 $\mathrm{S}$ ), which may be an eastward extension of the tropical storm track. In general, track densities equatorward of $40^{\circ} \mathrm{S}$ are uniform, with an exception of near the continental heat low (centered near $15^{\circ} \mathrm{S}, 130^{\circ} \mathrm{E}$ ), which is likely connected with the bowing of isentropes toward (and sometimes intersection with) the earth's surface. The heat low is not evident at $330 \mathrm{~K}$ (Fig. 3b), where the track density tends to decrease gradually away from the tropical storm track. At the upper level $(350 \mathrm{~K}$, Fig. 3c) there is also a subtropical track density maximum near $35^{\circ} \mathrm{S}$, which peaks over southwestern and southeastern Australia. These are preferred regions for the breaking of extratropical Rossby waves (e.g., Postel and Hitchman 1999). The maximum presumably reflects the formation of isolated PV maxima from the breaking waves.

The origin of a coherent PV maximum is defined as the first location at which its track was recorded. Figures $3 \mathrm{~d}-\mathrm{f}$ shows the genesis count at each grid point in the ERA-Interim dataset at each of the three levels. Generally, the high genesis regions are close to the high 

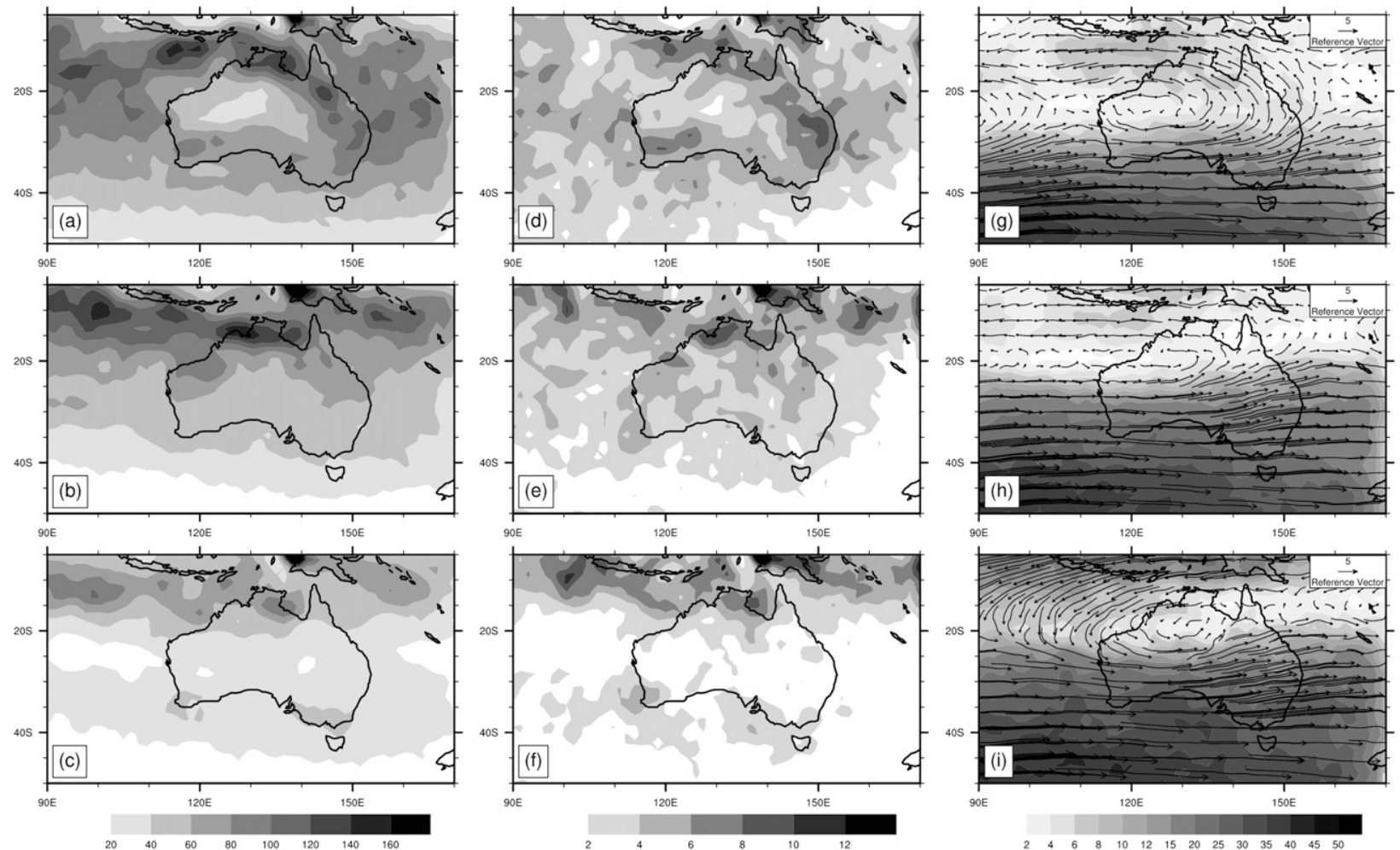

FIG. 3. Statistics of tracking at each of the ERA-Interim grid points at (top) 315, (middle) 330, and (bottom) $350 \mathrm{~K}$. (left) Track density at the ERA-Interim grid points (total number of tracks for the period 1989-2009). (middle) Count of initial locations of PV maxima (i.e., first tracked location using all tracks during the period 1989-2009) on the ERA-Interim grid points. (right) Propagation speed (shaded, $\mathrm{m} \mathrm{s}^{-1}$ ) and direction (vector) averaged across all tracks for 1989-2009. Legends for each field are displayed at the bottom of each column.

track densities, shown in Figs. 3a-c, with a tendency for the genesis to peak upstream of the maximum track densities (cf. Figs. 3g-i). This indicates that most maxima originate in the storm tracks. The main exception to this is found at $315 \mathrm{~K}$ (Fig. 3d), where there is a genesis maximum over southern Queensland (near $30^{\circ} \mathrm{S}, 150^{\circ} \mathrm{E}$ ), away from a corresponding track density maximum. The location of this genesis maximum relative to the track density maximum and the mean flow suggests that, although coherent PV maxima form over southern Queensland, they are subsequently advected northwestward into the tropics. This motion is summarized in Figs. $3 \mathrm{~g}-\mathrm{i}$, which displays the mean motion vector of all tracked PV maxima at each gridpoint on the three isentropic levels. At all levels poleward of about $25^{\circ} \mathrm{S}$ the motion of coherent PV centers is predominantly from west to east and equatorward of this latitude the motion is generally slower and in the opposite direction. In the tropics on the 315-K level, the motion vectors show that PV maxima move equatorward over the eastern half of the Australian continent and curve anticyclonically toward the monsoon region. PV maxima within the monsoon accelerate westward and attain their peak motion (approximately $10 \mathrm{~m} \mathrm{~s}^{-1}$ ) over the Timor Sea. This is consistent with the broad anticyclonic flow associated with the heat troughs over northern Australia (see, e.g., Arnup and Reeder 2007) and indicates that PV maxima at $315 \mathrm{~K}$ frequently move from the subtropics into the tropics. There is little evidence at $330 \mathrm{~K}$ (Fig. 3h) of similar behavior over eastern Australia. Instead, the mean motion of the PV maxima in the tropics is generally slowly westward, with maximum motion again over the Timor Sea. At the uppermost level (Fig. 3i) the mean motion vectors over much of northern Australia are very small with a slight preference for westward motion. However, the mean motion within $5^{\circ}$ of the equator is strongly westward, and over the eastern Indian Ocean (west of about $115^{\circ} \mathrm{E}$ ) the PV maxima move poleward, consistent with mean upper-level divergence near the equator. This contrasts with PV maxima at $315 \mathrm{~K}$ over eastern Australia where PV maxima tend to move from the subtropics into the tropics.

\section{b. PV centers in the Australian monsoon region}

For tracking purposes, an "Australian monsoon region" is defined by the box extending from $10^{\circ}$ to $20^{\circ} \mathrm{S}$, 

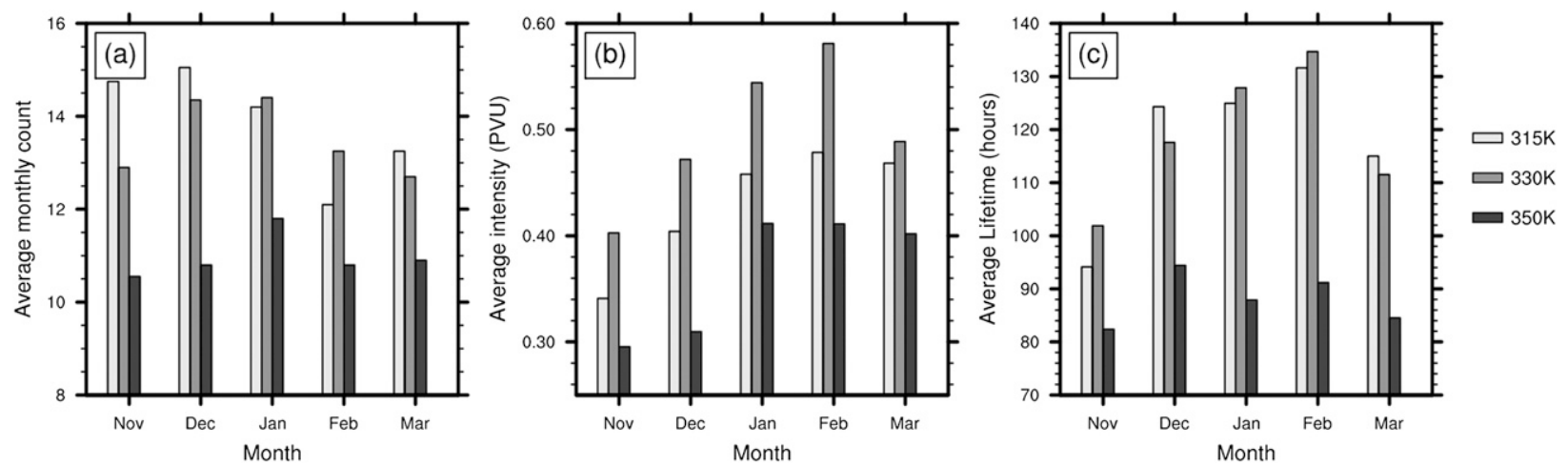

FIG. 4. Monthly mean statistics of coherent PV maxima in the Australian monsoon (defined as the region $10^{\circ}-20^{\circ} \mathrm{S}, 120^{\circ}-147.5^{\circ} \mathrm{E}$ ) at each of the three isentropic levels. (a) Average system count, (b) average system intensity (PVU), and (c) average length of track (hours).

$120^{\circ}$ to $147.5^{\circ} \mathrm{E}$ and is overlaid on the tracking example shown in Fig. 2. Using the PV track data, the PV maxima passing through the Australian monsoon are extracted. Figure 4a shows the average number of individual PV maxima at each level in the monsoon region for each month. The number of systems at 315 and $330 \mathrm{~K}$ are similar and there are approximately $50 \%$ fewer systems tracked at $350 \mathrm{~K}$ in all of the months. There is little month-to-month variability in the number of systems tracked at any of the levels; over the warm season there are approximately 13 coherent PV maxima per month at 315 and $330 \mathrm{~K}$ and 11 per month at $350 \mathrm{~K}$. This result suggests that on average there is a coherent PV maximum within the monsoon region every $2-3$ days. Although there is little month-to-month variability in the number of PV maxima, there is variability in their intensity, which is shown in Fig. 4b. In all months the PV maxima are most intense at $330 \mathrm{~K}$ and least intense at $350 \mathrm{~K}$, consistent with the structure shown for one intense Australian monsoon depression by Hell and Smith (1998). At all three levels the mean intensity increases from November and peaks in February with an overall increase of around $50 \%$. The mean lifetime of PV maxima, defined as the length of track in hours of each $\mathrm{PV}$ maxima that passes through the monsoon box, is shown in Fig. 4c. Again, the properties of the PV maxima at 315 and $330 \mathrm{~K}$ are similar; at both levels the mean lifetime is between 4 and 5 days with peak lifetimes in February when the mean intensities peak (Fig. 4b). The mean lifetime is shorter and less variable at $350 \mathrm{~K}$ with values remaining close to 3.5 days throughout the season.

\section{c. Relationship to climate indices}

Rainfall variability in Australia has been linked with remote processes-often termed climate drivers. In particular, Risbey et al. (2009) noted that tropical modes of variability-namely, the El Niño-Southern Oscillation (ENSO), the Indian Ocean dipole (IOD) and the
Madden-Julian oscillation (MJO) - were correlated with changes in Australian rainfall. To determine if these drivers affect the number of PV maxima, the values of standard climate indices when each PV maximum is first detected in the monsoon region is determined. Histograms showing the relative frequency of occurrence of the standardized Southern Oscillation index (SOI) obtained from National Centers for Environmental Prediction (NCEP) and Indian Ocean dipole mode index (obtained from http://www.jamstec.go.jp/frcgc/research/ d1/iod/HTML/Dipole\%20Mode\%20Index.html), when PV maxima are first detected in the monsoon region, are shown in Figs. 5a,b. In each panel, the mean NovemberMarch frequency distribution of the indices is shown by a line for comparison. For the SOI (Fig. 5a) PV maxima are most frequent in periods with very slight (between -0.5 and 0 ) negative ENSO phases and weak La Niña conditions (SOI between +1 and +1.5 ). However, the distribution when PV maxima are present mirrors the seasonal mean distribution of SOI values, indicated by the line drawn on Fig. 5a. Similarly for the IOD index, the PV maxima occur most frequently when this index is close to zero (neutral) closely matching the seasonal mean distribution. To determine the effect of the MJO, the multivariate MJO index, devised by Wheeler and Hendon (2004), is utilized. Unlike the standardized SOI and IOD indices, this index separates the MJO into eight different phases representing the geographical location of MJO convection. The number of PV maxima present in the monsoon region in each MJO phase is displayed in Fig. 5c. Unlike the standardized indices shown in Figs. 5a,b, Fig. 5c suggests that the number of PV maxima does vary with the phase of the MJO. In the November-February mean phases 3-5 combined occur $38 \%$ of the time, but $43 \%$ of PV maxima are present in these phases, whereas the phases 1,7 , and 8 combined occur $37 \%$ of the time, but only $31 \%$ of PV maxima occur during these phases. Composites based 

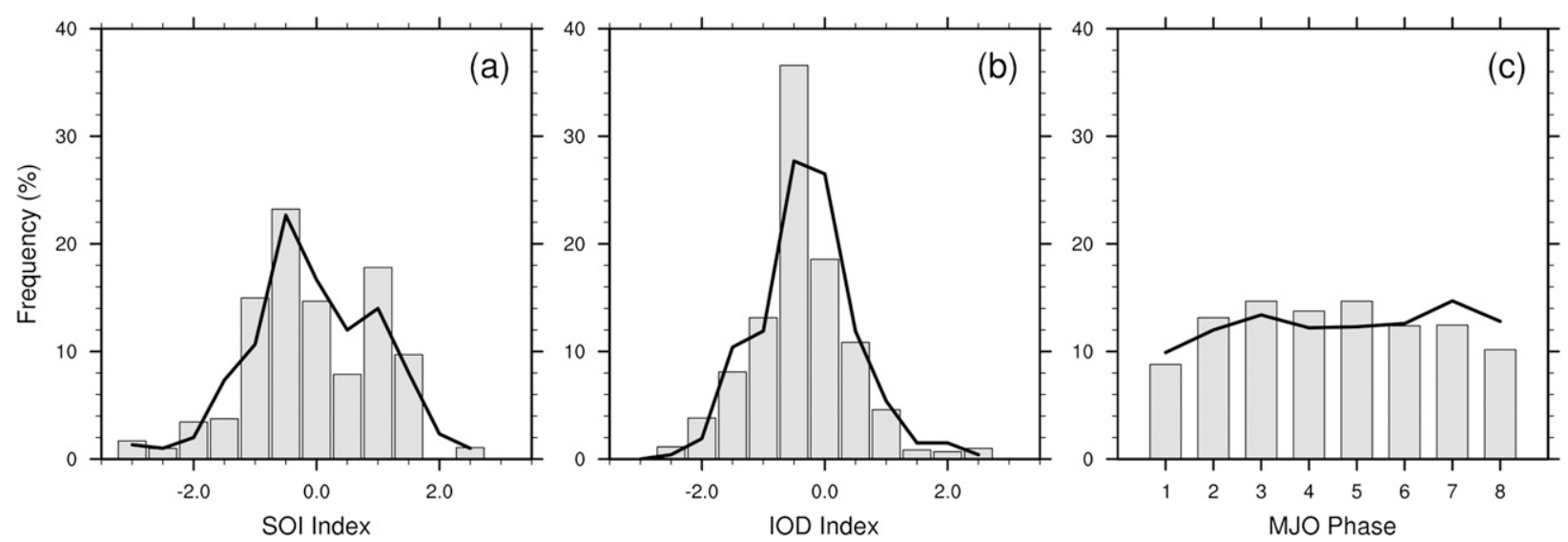

FIG. 5. Histograms showing the frequency of occurrence of coherent PV maxima at $315 \mathrm{~K}$ in the Australian monsoon (defined as the region $10^{\circ}-20^{\circ} \mathrm{S}, 120^{\circ}-147.5^{\circ} \mathrm{E}$ ) for November-March as a function of different climate indices. (a) Standardized Southern Oscillation index (SOI), (b) standardized Indian Ocean dipole (IOD) mode index, and (c) real-time multivariate MJO index. Overlaid lines shows the climatological frequency of the different climate indices in the November-March period.

upon these phases (Wheeler et al. 2009) show that phases 3-5 are associated with negative outgoing longwave radiation (OLR) anomalies and phases 1 and 8 are associated with positive OLR anomalies over northern Australia. Overall, these results indicate that PV maxima are more common during the convective phase of the MJO, while their numbers do not change greatly with changes in ENSO or the IOD.

\section{d. Temporal behavior}

As noted in the introduction, previous studies (e.g., Dickinson and Molinari 2000) find that there is a relative lack of activity on synoptic time scales in the Australian monsoon when compared to the West African monsoon, which is the closest geographical analog. Such findings contradict the PV tracking statistics, which suggest that on average there will be a PV maximum in the monsoon region every 2-3 days. Earlier studies have tended to reach their conclusions from calculations of power spectra, which implicitly assume that variations in the wind or precipitation field associated with the synoptic disturbances are periodic. Consequently, the difference in the conclusions reached may be related to the distribution of disturbances in time. To test this hypothesis, the interval between the passage of consecutive coherent $\mathrm{PV}$ maxima in a $5^{\circ}$ wide box $\left(10^{\circ}-20^{\circ} \mathrm{S}, 125^{\circ}\right.$ $130^{\circ} \mathrm{E}$ ) is computed and shown as a histogram in Fig. 6a. For comparison, the same calculation is made using identical PV maxima tracking performed over West Africa during the period May-October for the box $5^{\circ}-$ $15^{\circ} \mathrm{N}, 0^{\circ}-5^{\circ} \mathrm{E}$ and shown in Fig. $6 \mathrm{~b}$. In the case of the Australian monsoon (Fig. 6a), there is a preference for the mean interval to be 1-4 days, but there are also a significant number of cases where the interval was 10 days or more. This wide spread of intervals contrasts strongly with PV tracking carried out over West Africa (Fig. 6b) where intervals of 1-5 days account for more than $90 \%$ of cases. This result implies that PV maxima over Australia tend to be clustered in time punctuated by quiescent periods of varying length. A lack of clear periodicity means that power spectra of various fields are not representative of the true synoptic activity of the region. This episodic nature of PV maxima is consistent with observations of discrete active and break periods of the Australian monsoon (Suppiah 1992) and the large-scale structure of the Australian monsoon that is less conducive to the growth of periodic synopticscale weather systems [i.e., easterly waves, see Dickinson and Molinari (2000)].

\section{Composite synoptic structure}

The composite structure of all 315-K PV maxima passing through the box $10^{\circ}-20^{\circ} \mathrm{S}, 125^{\circ}-130^{\circ} \mathrm{E}$ (box shown on Fig. 2) at $315 \mathrm{~K}$ is shown in Fig. 7. In total, this composite comprises 454 individual cases. Composites on other levels give virtually identical results as the PV maxima tend to be vertically aligned (cf. Figs. 7c,d). The location of the box is selected as there is a relatively dense observation network in this region, including regular soundings from Darwin $\left(12.5^{\circ} \mathrm{S}, 130.9^{\circ} \mathrm{E}\right)$; thus it is expected that the ERA-Interim data are highly constrained by observations. This region is close to the track density maximum at 315 and $330 \mathrm{~K}$ (Figs. 3a,b) and close to where PV maxima moving through the monsoon cross from land to ocean (see Figs. $3 \mathrm{~g}-\mathrm{i}$ ).

As anticipated from the tracking technique, the composite 315-K PV maximum (Fig. 7a) is marked by 

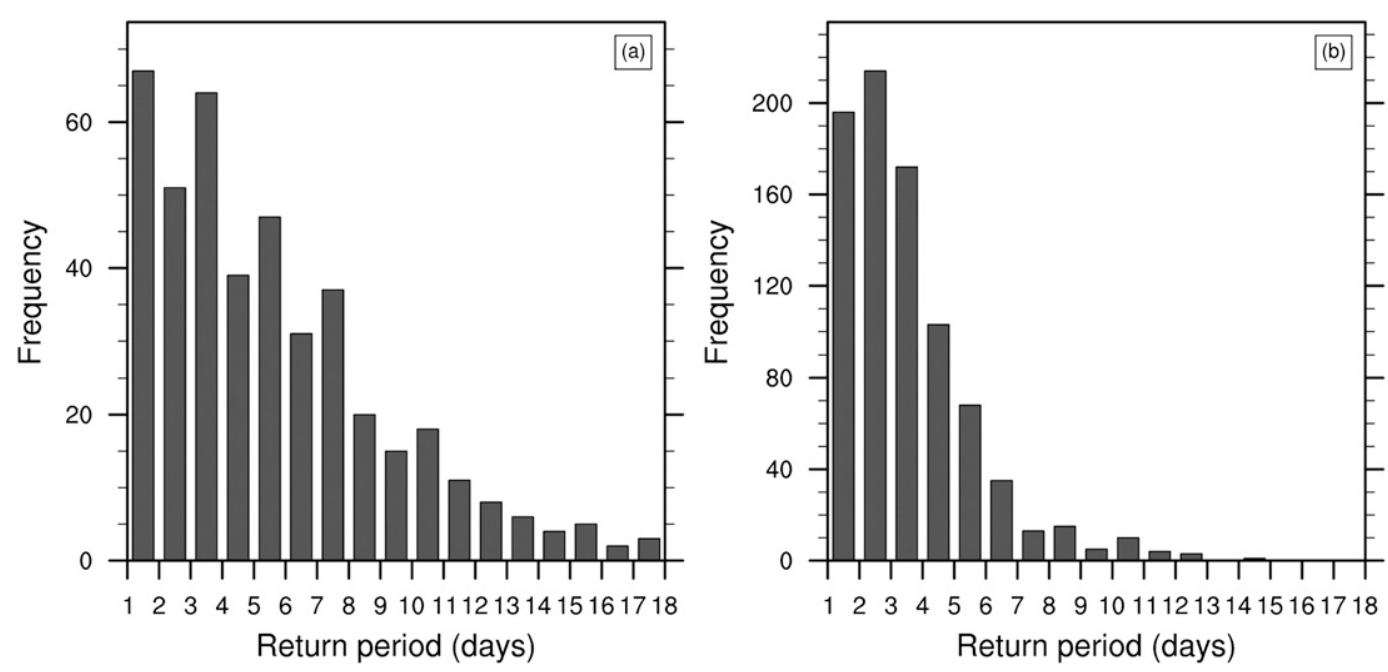

FIG. 6. Histograms of the time interval (days) between consecutive coherent PV maxima over (a) northern Australia $\left(10^{\circ}-20^{\circ} \mathrm{S}, 125^{\circ}-130^{\circ} \mathrm{E}\right)$ and (b) West Africa $\left(5^{\circ}-15^{\circ} \mathrm{N}, 0^{\circ}-5^{\circ} \mathrm{E}\right)$.

a closed contour of PV exceeding 0.3 PVU near $130^{\circ} \mathrm{E}$. The disturbance is on the order of $1000 \mathrm{~km}$ across, similar to subsynoptic-scale PV maxima embedded within African easterly waves (Berry and Thorncroft 2005). The PV maximum is located at the end of a region of relatively high PV that extends northwestward from central Queensland, approximately following the composite $315-\mathrm{K}$ flow vectors. The composite GPCP anomaly shows that the PV maximum is collocated with a significant modulation of the mean rainfall; an area of enhancement of similar size to the PV maximum and peaking near $3 \mathrm{~mm}$ day $^{-1}$ is found on the western (downstream) side of the PV maximum. Given that isentropes slope downward and poleward (toward the inland desert) in the presence of cyclonic flow around the PV maximum, this rainfall occurs in a region of mean isentropic ascent. There are areas of suppressed rainfall of similar size and amplitude both upstream and downstream of the PV maxima (near $120^{\circ}$ and $140^{\circ} \mathrm{E}$ ), suggesting that the disturbance has a characteristic length scale of around $2000 \mathrm{~km}$, which is less than that of composite African easterly waves (e.g., Reed et al. 1977). A positive rainfall anomaly is also located over Papua New Guinea in this composite, perhaps indicative of the distribution of disturbances relative to the phase of the MJO (see Fig. 5c).

The composite horizontal wind vectors with specific humidity and temperature fields at $900 \mathrm{hPa}$ are shown in Fig. 7b. The cyclonic circulation of the PV maxima is evident along the northern coast, although it is relatively weak with wind vectors on the order of $1 \mathrm{~m} \mathrm{~s}^{-1}$. The highest moisture content is located at low latitudes (equatorward of $10^{\circ} \mathrm{S}$ ), but there is a local maximum on the eastern side of the cyclonic circulation near Darwin. This is essentially in the wake of the highest rainfall rates (Fig. 7a), so this could reflect both increased local evaporation as well as advection of moisture from the adjacent ocean. Although the magnitude of the wind vectors is small, the flow pattern around the disturbance acts across the gradients of specific humidity and advects moisture into the interior of the Australian continent. The advection of moisture, especially from around the Gulf of Carpentaria, was found to be a key component in promoting rainfall in the interior of the continent by Berry et al. (2011b), who speculated that transient synoptic disturbances modulate the moisture transport in the manner shown by the composite wind pattern in Fig. $7 \mathrm{~b}$ and increase the likelihood of rainfall in the desert interior.

Vertical cross sections of PV and wind through the center of the composite PV maximum $\left(14^{\circ} \mathrm{S}, 130^{\circ} \mathrm{E}\right)$ in the zonal and meridional plane are displayed in Figs. 7c,d. The PV maximum shows no preferred vertical tilt and is maximized just below $500 \mathrm{hPa}(5 \mathrm{~km}$, approximately $330 \mathrm{~K}$ ), with relatively low values above and below this level. Poleward of the disturbance (Fig. 7d) the boundary layer of the interior desert is marked by near-zero PV values up to $\sim 700 \mathrm{hPa}$ as a result of low static stability associated with the well-mixed boundary layer. Strong horizontal PV gradients exist at upper levels in high latitudes in association with the subtropical jet stream. Around the tropical PV maximum, the strongest winds are found near $700 \mathrm{hPa}$ close to the strongest horizontal PV gradient on the periphery of the desert boundary layer. There is a weak jet (peak zonal wind values around $7 \mathrm{~m} \mathrm{~s}^{-1}$ ) poleward of and 

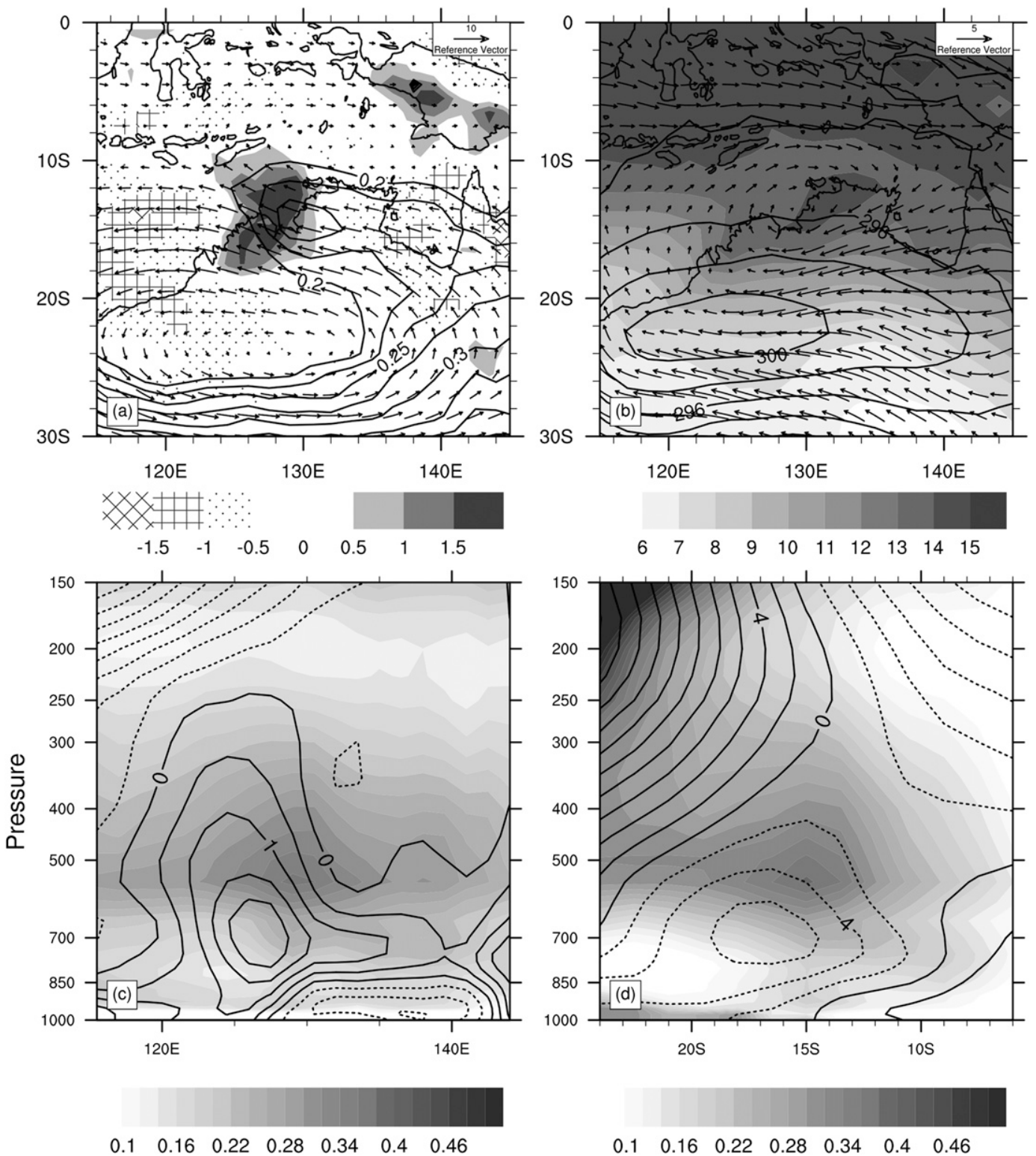

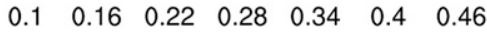

FIG. 7. Composite synoptic structure of all tracked $315-\mathrm{K}$ PV maxima passing through the box $10^{\circ}-20^{\circ} \mathrm{S}, 125^{\circ}-$ $130^{\circ} \mathrm{E}$ (454 cases): (a) 315-K PV (contoured every 0.1 PVU greater than $0.2 \mathrm{PVU}$ ) and wind vectors overlaid on rainfall anomaly from time-varying GPCP climatology $\left(\mathrm{mm}_{\text {day }}{ }^{-1}\right.$ ); (b) 900-hPa mixing ratio (shaded, $\mathrm{g} \mathrm{kg}^{-1}$ ) wind vectors and potential temperature (black contours, K); (c) vertical cross section taken west-east along $14^{\circ} \mathrm{S}$ showing PV (shaded, PVU) and meridional wind (black contours, dashed negative; $\mathrm{m} \mathrm{s}^{-1}$ ); and (d) vertical cross section taken south-north along $130^{\circ}$ E showing PV (shaded, PVU) and zonal wind (black contours, dashed negative; $\mathrm{m} \mathrm{s}^{-1}$ ).

below the PV maximum (Fig. 7d), with relatively weak zonal winds elsewhere near the disturbance. Southerlies around $2 \mathrm{~m} \mathrm{~s}^{-1}$ exist on the western (downstream) flank of the PV maximum, again where the horizontal PV gradients are strongest. Ahead of the PV maximum, southerly winds still are evident up to $\sim 300 \mathrm{hPa}$, and there is some hint of the relative maximum tilting against the mean zonal shear (Fig. 7d). Behind the PV maximum the meridional flow is relatively weak at the latitude of the cross section, although there is a shallow layer of northerlies up to the $850-\mathrm{hPa}$ level that could be regionally important for the transport of moisture (cf. Berry et al. 2011b). This composite PV maximum is located in a monsoon environment and is associated with a maximum in rainfall. Consequently, it is expected that the vertical distribution of $\mathrm{PV}$ is, in part, determined by the profile of diabatic heating. To first order, the effect of latent heating on the PV field is to generate cyclonic 
PV where the vertical gradient of heating is positive and to destroy it where the vertical gradient is negative, effectively redistributing cyclonic PV along the negative of the local absolute vorticity vector. The PV distribution shown in Fig. $7 \mathrm{c}$ is consistent with a peak in diabatic heating near $8 \mathrm{~km} \mathrm{(300} \mathrm{hPa)} \mathrm{and} \mathrm{peak} \mathrm{diabatic} \mathrm{cooling}$ near $2 \mathrm{~km}$ (approximately $850 \mathrm{hPa}$ ). This is essentially the heating profile associated with deep organized convection in the tropics (e.g., Houze 1982, 1989; Mapes and Houze 1995; Jakob and Schumacher 2008), suggesting that at this stage of the PV maximum life cycle convective processes play an important role.

The time evolution of the composite $\mathrm{PV}$ maximum is shown in Fig. 8 through a lag composite for all 315-K PV maxima passing through the box $10^{\circ}-20^{\circ} \mathrm{S}, 125^{\circ}-130^{\circ} \mathrm{E}$ (as in Fig. 7). This figure displays the $315-\mathrm{K}$ PV and GPCP rainfall anomaly (as a percentage change from the time-varying mean) for the three days prior to and after PV maxima are located in the composite box. At -3 days (Fig. 8a) relatively high PV extends around the subtropical heat low, but there are no positive precipitation anomalies in the tropics. The first clear indication of a coherent PV maximum in the tropics becomes evident at day -2 , when a closed PV contour becomes defined in the Gulf of Carpentaria and positive rainfall anomalies exist over the Top End of the Northern Territory (near $15^{\circ} \mathrm{S}, 135^{\circ} \mathrm{E}$ ). Over the following days, this $\mathrm{PV}$ maximum and the associated positive rainfall anomaly become better defined and propagate westward, passing through the composite box at day zero (by design, Fig. 8d). Over the next three days (Figs. 8e-g), the PV maximum and rainfall anomaly are still evident and continue to propagate westward into the Indian Ocean. If it is assumed that all the rainfall within the composite box from day -1 to day +1 can be attributed to the presence of the PV maxima and, by multiplying this amount by the total number of cases during the GPCP data period, it is estimated that approximately $40 \%-50 \%$ of the total summertime rainfall occurs in association with a tracked PV maximum.

While the time evolution of the PV maximum is perhaps unremarkable, given the composite shown in Fig. 7, the fields shown in Fig. 8 also indicate a coherent phase relationship between PV maxima and extratropical weather systems in the mean. At -3 days a synopticscale area of enhanced rainfall is evident over the southern part of the Australian continent, centered near $30^{\circ} \mathrm{S}, 130^{\circ} \mathrm{E}$, and further analysis (not shown) suggests this anomaly is also present near $40^{\circ} \mathrm{S}$. This rainfall anomaly has its major axis orientated northwest-southeast, which is consistent with that of midlatitude fronts in this region. This rainfall anomaly progresses eastward coherently with time such that it reaches southeastern Australia at lag zero, which shows that there is a preferred midlatitude synoptic pattern when there is a PV maximum in northwestern Australia. A similar result was found by Berry et al. (2011b), who noted that rainfall over the interior of northwestern Australia during summer was more likely to occur with a synoptic low over southeastern Australia. Another link to the extratropics is noted on the western side of the continent. From approximately day -2 to day +2 there is a positive rainfall anomaly in the eastern Indian Ocean extending from $10^{\circ} \mathrm{S}$ toward southwestern Australia that is most prominent at lag zero. This rainfall anomaly could be associated with fronts (Berry et al. 2011a,c) or cloud bands (Tapp and Barrell 1984). At day +1 and +2 a large positive rainfall anomaly develops close to the center of the inland heat low and by day +3 there is a contiguous area of positive rainfall anomaly reminiscent of a northwest cloud band extending southeastward from the Indian Ocean toward the Australian Bight.

\section{Discussion and conclusions}

Using an objective tracking scheme applied to reanalysis data, the statistics and main characteristics of synoptic-scale disturbances in the Australian monsoon region have been calculated. One of the key findings is that coherent, long-lived PV maxima are present over northern Australia throughout the summer. This result contradicts previous work (e.g., Dickinson and Molinari 2000), which found relatively little synoptic activity in this region. It appears that this difference may be an artifact of analysis techniques that rely on bandpass filtering to describe synoptic activity. It has been found here that the occurrence of PV maxima is episodic and is unlikely to be well captured by filtering that assumes that the phenomena are periodic. The systems associated with the PV maxima are regionally important as they significantly modulate the mean rainfall (see, e.g., Fig. 7a). Moreover, it is estimated that on the order of half of the summertime rainfall in parts of northwestern Australia occurs in the vicinity of the tracked PV maxima.

The mean geographical distribution of PV centers (Fig. 3) showed that a significant proportion of the tropical PV maxima are first identified within the monsoon region itself, especially around the Gulf of Carpentaria, and then propagate westward with the mean flow. According to the NOAA optimum interpolation sea surface temperature dataset (Reynolds et al. 2002), the southern Gulf of Carpentaria has the highest Januarymean sea surface temperatures on the globe (near $31^{\circ} \mathrm{C}$ ). The gulf is bounded by convectively active regions (Pope et al. 2008) on three sides, including the upstream 

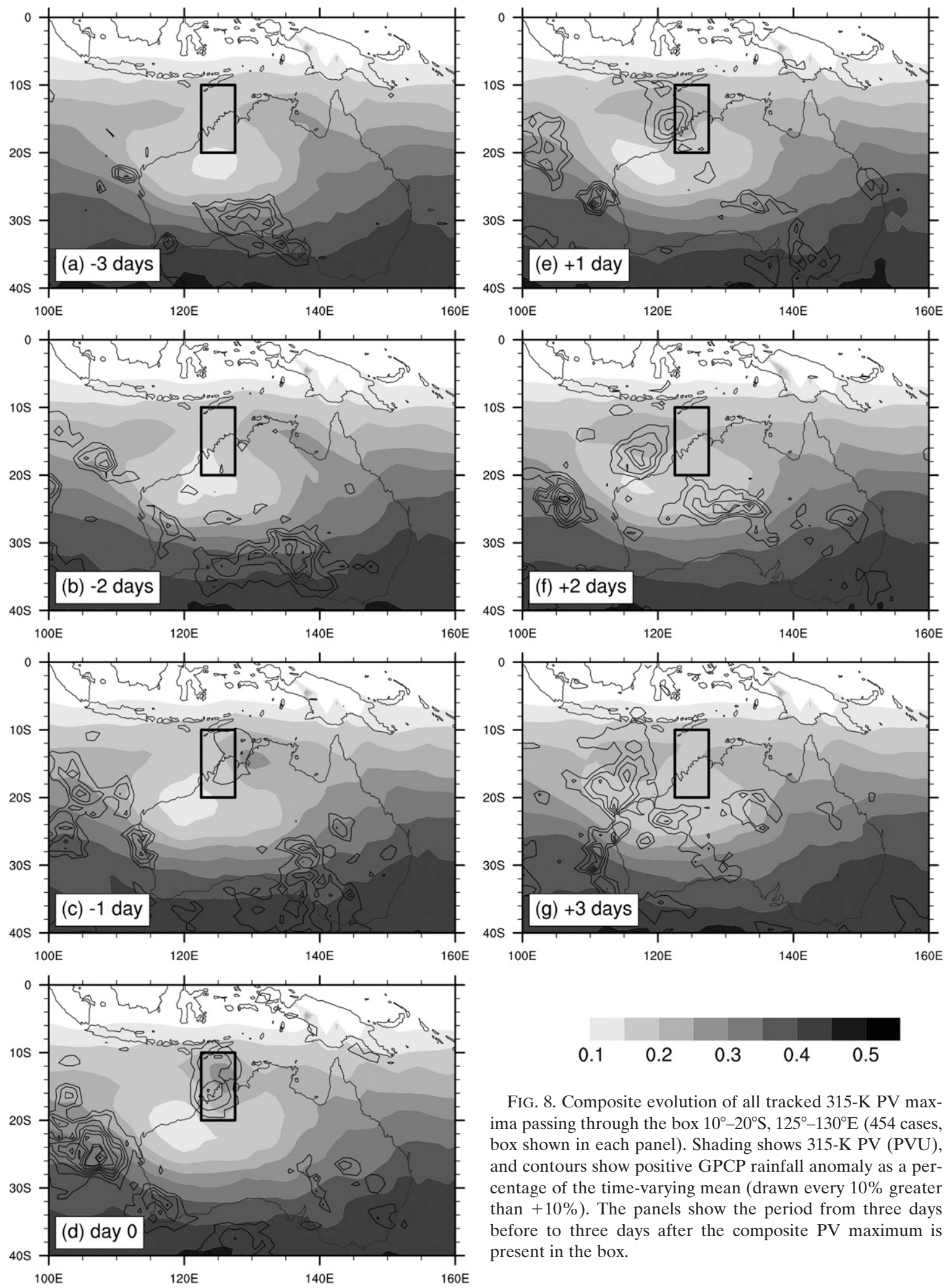

FIG. 8. Composite evolution of all tracked 315-K PV maxima passing through the box $10^{\circ}-20^{\circ} \mathrm{S}, 125^{\circ}-130^{\circ} \mathrm{E}$ (454 cases, box shown in each panel). Shading shows 315-K PV (PVU), and contours show positive GPCP rainfall anomaly as a percentage of the time-varying mean (drawn every $10 \%$ greater than $+10 \%$ ). The panels show the period from three days before to three days after the composite PV maximum is present in the box. 
(eastern) side. Therefore, it is likely that organized convection is sometimes of sufficient scale to diabatically generate subsynoptic-scale PV maxima in this region, which may persist for longer than the parent convection. The possibility of in situ diabatic PV generation is supported by the composite vertical profiles of PV shown in Figs. 7c,d and the finding that PV maxima are around $50 \%$ more frequent in the convectively active phase of the MJO. The PV maxima storm track shown in Fig. 3 is collocated with a maximum in the mesoscale convective complex population described by Laing and Fritsch (1997, their Fig. 4) and propagate in the same direction. Although it might be tempting to view these disturbances as being the dynamic response to organized convection, it is important to consider that the horizontal scale of the PV maxima is larger than that of a typical mesoscale convective vortex (see, e.g., Houze 2004) and the rainfall rate is modulated over a large area (Fig. 7a). Additionally, rainfall is enhanced most where quasigeostrophic theory predicts ascent (i.e., ahead of the disturbance) and the meridional wind field, shown in Fig. 7c, appears to exhibit some evidence of a vertical tilt that is against the shear, which is consistent with baroclinic energy conversion on the synoptic scale. In many aspects, these Australian systems resemble African easterly waves, albeit with significantly smaller amplitudes (cf. Reed et al. 1977). The Australian systems propagate through a similar environment and have largest perturbations to the wind field at the level of a midtropospheric jet, along with enhanced of rainfall ahead of the disturbance. It has been recently suggested that African easterly waves are akin to diabatic Rossby waves (Berry and Thorncroft 2012) in that they are a synoptic feature where both adiabatic and diabatic processes are equally important. It is hypothesized that Australian systems are similar, although with diabatic processes playing a larger relative role due to the background basic state having weaker gradients in the PV.

Perhaps the most intriguing result presented here is the apparent connection between extratropical disturbances and the coherent PV maxima in the monsoon region. The geographic distribution at $315 \mathrm{~K}$ (Fig. 3) shows that there is a PV maxima genesis peak over Queensland at $315 \mathrm{~K}$ and these maxima move northwestward, approximately following the coastline. This region is on the equatorward (anticyclonic shear) side of the exit of the mean subtropical jet (e.g., Nakamura and Shimpo 2004) where extratropical Rossby waves are most likely to overturn and break (see, e.g., Postel and Hitchman 1999). It is hypothesized that the PV maxima that are first detected over Queensland could form as a result of Rossby wave breaking along the eastern coast of Australia; effectively these maxima are the debris of wave breaking, which are subsequently transported into the tropics by the large-scale flow. Once in the tropics these extratropical features could act as the focus for convection and further intensify through diabatic processes. This may, in part, explain the episodic nature of the tropical PV maxima as Rossby wave breaking is nonlinear and irregular. Further evidence for a strong link with the extratropics is shown in the lag composite (Fig. 8), where the coherent progression of extratropical features poleward of about $30^{\circ} \mathrm{S}$ features is clearly evident. Because the composite is based on a large number of cases (454), it implies that there is a definite preferred phasing of extratropical systems and PV maxima in the monsoon. Together these results allow the construction of a conceptual model. In general, if there is a cyclone (and rainfall) in the Great Australian Bight, there is likely to be an anticyclone over southeastern Australia. If this anticyclone were part of a breaking Rossby wave, filaments of cyclonic PV would extend around the eastern periphery of the anticyclone into tropical Queensland. Furthermore, if these filaments were to wrap up and break off into coherent maxima, they could be advected around the periphery of the anticyclone into the tropics to become one of the tracked features. The feature might then act as a focus for convection and intensify through diabatic processes as it is advected through the monsoon region toward the eastern Indian Ocean.

When interpreting the results presented here, the limitations of the tracking technique must be recognized. In particular, the tracking requires a closed contour of PV exceeding 0.01 PVU on an isentropic surface. Although this ensures that the maxima are coherent, it means that the history of a particular disturbance may be shorter than what one might estimate subjectively. If PV maxima are the debris of breaking waves in the extratropics, this feature will only be tracked when it becomes an isolated PV maximum, so the upstream history is not recorded. Therefore, the statistics might be an underestimate of the number of PV maxima that are linked to features in the extratropics. It is suggested that future work should examine the process of the tropical transition of extratropical features including how this has changed recently and how it might change in a future climate. The obvious benefits are that an understanding of this process will assist tropical weather forecasting and may reveal a cause of the recent rainfall trends in parts of northern Australia.

Acknowledgments. Reanalysis data for this study was provided by the ECMWF. Satellite imagery, GPCP rainfall, and TRMM data were obtained from NASA Goddard Earth Sciences Data and Information Service 
Center. The authors thank Thomas Spengler and one anonymous reviewer for their input and improvements in the manuscript. This study is supported by the Australian Research Council through Grant DP0985665, "Rainfall over the Maritime Continent and Northern Australia.'

\section{REFERENCES}

Arnup, S. J., and M. J. Reeder, 2007: The diurnal and seasonal variation of the northern Australian dryline. Mon. Wea. Rev., 135, 2995-3008.

Berry, G. J., and C. Thorncroft, 2005: Case study of an intense African easterly wave. Mon. Wea. Rev., 133, 752-766.

- , and 2012: African easterly wave dynamics in a mesoscale numerical model: The upscale role of convection. J. Atmos. Sci., 69, 1267-1283.

— C. Jakob, and M. Reeder, 2011a: Recent global trends in atmospheric fronts. Geophys. Res. Lett., 38, L21812, doi:10.1029/ 2011GL049481.

— - M. J. Reeder, and C. Jakob, 2011b: Physical mechanisms regulating summertime rainfall over northwestern Australia J. Climate, 24, 3705-3717.

- - _ and - 2011c: A global climatology of atmospheric fronts. Geophys. Res. Lett., 38, L04809, doi:10.1029/ 2010 GL046451.

Carlson, T. N., 1969: Synoptic histories of three African disturbances that developed into Atlantic hurricanes. Mon. Wea. Rev., 97, 256-276.

Davidson, N. E., and G. J. Holland, 1987: A diagnostic analysis of two intense monsoon depressions over Australia. Mon. Wea. Rev., 115, 380-392.

Dickinson, M., and J. Molinari, 2000: Climatology of sign reversals of the meridional potential vorticity gradient over Africa and Australia. Mon. Wea. Rev., 128, 3890-3900.

Godbole, R. V., 1977: The composite structure of the monsoon depression. Tellus, 29, 25-40, doi:10.1111/j.2153-3490.1977. tb00706.x

Hell, R., and R. K. Smith, 1998: A monsoon depression over northwestern Australia part I: Case study. Aust. Meteor. Mag., 47, 21-40

Houze, R. A., Jr., 1982: Cloud clusters and large-scale vertical motions in the tropics. J. Meteor. Soc. Japan, 60, 396-410.

— 1989: Observed structure of mesoscale convective systems and implications for large-scale heating. Quart. J. Roy. Meteor. Soc., 115, 425-461, doi:10.1002/qj.49711548702.

_ 2004: Mesoscale convective systems. Rev. Geophys., 42, RG4003, doi:10.1029/2004RG000150.

Huffman, G. J., and Coauthors, 1997: The Global Precipitation Climatology Project (GPCP) combined precipitation dataset. Bull. Amer. Meteor. Soc., 78, 5-20.
— , and Coauthors, 2007: The TRMM Multisatellite Precipitation Analysis (TMPA): Quasi-global, multiyear, combined-sensor precipitation estimates at fine scales. J. Hydrometeor., 8, 38-55.

Jakob, C., and C. Schumacher, 2008: Precipitation and latent heating characteristics of the major tropical western Pacific cloud regimes. J. Climate, 21, 4348-4364.

Kong, Q., and S.-X. Zhao, 2010: Heavy rainfall caused by interactions between monsoon depression and middle-latitude systems in Australia: A case study. Meteor. Atmos. Phys., 106, 205-226.

Krishnamurti, T. N., M. Kanamitsu, R. Godbole, C.-B. Chang, F. Carr, and J. H. Chow, 1975: Study of a monsoon depression (I): Synoptic structure. J. Meteor. Soc. Japan, 53, 227-239.

Laing, A. G., and J. M. Fritsch, 1997: The global population of mesoscale convective complexes. Quart. J. Roy. Meteor. Soc., 123, 389-405.

Mapes, B. E., and R. A. Houze Jr., 1995: Diabatic divergence profiles in western Pacific mesoscale convective systems. J. Atmos. Sci., 52, 1807-1828.

Nakamura, H., and A. Shimpo, 2004: Seasonal variations in the Southern Hemisphere storm tracks and jet streams in a reanalysis dataset. J. Climate, 17, 1828-1844.

Norquist, D. C., E. E. Recker, and R. J. Reed, 1977: The energetics of African wave disturbances as observed during phase III of GATE. Mon. Wea. Rev., 105, 334-342.

Pope, M., C. Jakob, and M. J. Reeder, 2008: Convective systems of the north Australian monsoon. J. Climate, 21, 5091-5112.

Postel, G. A., and M. H. Hitchman, 1999: A climatology of Rossby wave breaking along the subtropical tropopause. J. Atmos. Sci., 56, 359-373.

Reed, R. J., D. C. Norquist, and E. E. Recker, 1977: The structure and properties of African wave disturbances as observed during phase III of GATE. Mon. Wea. Rev., 105, 317-333.

Reynolds, R. W., N. A. Rayner, T. M. Smith, D. C. Stokes, and W. Wang, 2002: An improved in situ and satellite SST analysis for climate. J. Climate, 15, 1609-1625.

Risbey, J., M. Pook, P. McIntosh, M. Wheeler, and H. Hendon, 2009: On the remote drivers of rainfall variability in Australia. Mon. Wea. Rev., 137, 3233-3253.

Suppiah, R., 1992: The Australian summer monsoon: A review. Prog. Phys. Geogr., 16, 283-318.

Tapp, R. G., and S. L. Barrell, 1984: The north-west Australian cloud band: Climatology, characteristics and factors associated with development. J. Climatol., 4, 411-424.

Wheeler, M. C., and H. H. Hendon, 2004: An all-season real-time multivariate MJO index: Development of an index for monitoring and prediction. Mon. Wea. Rev., 132, 1917-1932.

,-- S. Cleland, H. Meinke, and A. Donald, 2009: Impacts of the Madden-Julian oscillation on Australian rainfall and circulation. J. Climate, 22, 1482-1498.

Zhao, S., and G. A. Mills, 1991: A study of a monsoon depression bringing record rainfall over Australia. Part II: Synopticdiagnostic description. Mon. Wea. Rev., 119, 2074-2094. 